\title{
STRATEGI MENINGKATKAN CITRA PEMBELAJARAN IPS YANG BERMAKNA MENUJU ERA SOCIETY 5.0
}

\author{
Eko Suprayitno \\ Universitas Negeri Yogyakarta, Daerah Istimewa Yogyakarta \\ Email: pprayitno1996@gmail.com
}

\begin{abstract}
Abstrak
Penelitian ini bertujuan untuk memberikan informasi terkait strategi relevan yang kemudian diberdayakan untuk meningkatkan citra pembelajaran IPS yang bermakna menuju era society 5.0. Jenis penelitian yang digunakan ialah library research, dengan hasil sebagai berikut: (1) Pembelajaran IPS yang bermakna diharapkan dapat memberikan konsep pemahaman kepada siswa dalam mempelajari bahkan menemukan berbagai alternatif solusi terkait fenomena sosial maupun masalah sosial menuju era society 5.0, untuk itu kontribusi guru secara nyata didalam pembelajaran IPS perlu ditingkatkan sebagai dasar awal menuju ketercapaian pembelajaran yang bermakna, (2) Idealnya untuk menuju era society 5.0, guru IPS wajib mengoptimalkan praktik konsep belajar yang sesuai dengan karakteristik era society 5.0, (3) Menggunakan berbagai model pembelajaran yang berpusat pada siswa (student center learning) secara aktif, inovatif dan kreatif, memberdayakan pembelajaran berbasis teknlogi informasi dan komunikasi (ICT), dan memainkan peran penting dalam meningkatkan kualitas pembelajaran dengan senantiasa memperhatikan karakteristik masing-masing siswa secara kolektif.
\end{abstract}

Kata kunci: Society 5.0, Pembelajaran IPS Bermakna, Strategi Pembelajaran

\section{PENDAHULUAN}

Konsep era society 5.0 yang dicitacitakan oleh pemerintah Jepang lebih menekankan pada upaya menempatkan manusia sebagai pusat inovasi (human centered), era society 5.0 merupakan tatanan baru yang menarik dan penting untuk disikapi (Irawan, 2020), dimana antara dunia fisik dan dunia maya sangat terintegrasi (Salgues, 2018). Era society 5.0 dapat dilihat dengan ciri-ciri sebagai berikut: (1) menggunakan informasi lengkap dan teknologi komunikasi, (2) berpusat pada komunitas, (3) adanya partisipasi masyarakat (4) memiliki nilai yang sama: keberlanjutan, inklusif, efektif, dan kekuatan intelijen dan (5) terjadinya perkembangan gangguan pada aspek ekonomi (Salgues, 2018).

Era society 5.0 dimanfaatkan untuk meningkatkan kualitas hidup secara humanis dengan mengutamakan pengembangan inovasi ilmu pengetahuan dan teknologi pada semua aspek kehidupan manusia (Irawan, 2020).
Pernyataan tersebut didukung dengan pendapat (Fukuyama, 2018) bahwa manfaat dari era society 5.0 itu sendiri adalah untuk mewujudkan masyarakat dimana orang menikmati hidup sepenuhnya. Artinya, reformasi sosial (inovasi) dalam era society 5.0 akan mencapai masyarakat berwawasan kedepan yang meruntuhkan rasa disintegrasi yang ada, masyarakat yang anggotanya saling menghormati satu sama lain, melampaui generasi, dan masyarakat di mana setiap orang dapat memimpin kehidupan yang aktif dan menyenangkan.

Untuk menghadapi kompleksitas kondisi kehidupan era society 5.0, bidang pendidikan khususnya guru, diharapkan mampu bertindak secara intens dengan memberikan identifikasi secara dini terhadap era society 5.0 secara strategis kepada siswanya (Irawan, 2020), siswa tidak cukup dibekali dengan kemampuan membaca, menulis dan berhitung atau lebih dikenal dengan sebutan "Tree R" (reading, writing, arithmetic), tetapi juga 
perlu dibekali kompetensi masyarakat global atau juga disebut kecakapan abad 21, yakni dengan memberikan berbagai model pembelajaran komunikatif, kreatif, berpikir kritis, dan berkolaborasi atau dikenal dengan sebutan "Four Cs", yaitu communicators, creators, critical thingkers, and collaborators (National Education Association, 2017). Hadirnya era society 5.0 tentu akan berpengaruh pula pada semua aspek kehidupan tak terkecuali pada aspek pendidikan. Satu diantaranya yaitu pendidikan dalam pembelajaran IPS. Implikasi konsep era society 5.0 terhadap pembelajaran IPS diantaranya ialah perlu adanya transformasi citra pembelajaran kepada siswa untuk disesuaikan dengan kebutuhan hidup menuju era society 5.0.

Realita yang terjadi di sekolah, tidak semua siswa memiliki persepsi yang baik terhadap pembelajaran IPS. Pembelajaran IPS yang diimplementasikan guru masih cenderung bersifat model lama, Pernyataan tersebut didukung oleh temuan penelitian (Wulandari et al., 2018) menyatakan bahwa pembelajaran IPS di sekolah selalu disajikan dalam bentuk faktual, konsep yang kering, guru hanya mengejar target pencapaian kurikulum, tidak mementingkan proses. Pembelajaran IPS masih memiliki citra buruk apabila selalu menggunakan metode konvensional yang menjenuhkan dan hanya menekankan pada transfer pengetahuan (Mardiati \& Leba, 2018). Selain itu dalam pembelajaran IPS lebih menekankan pada aspek pengetahuan, fakta dan konsepkonsep yang bersifat hafalan belaka. Didukung pernyataan (Uge et al., 2019) bahwa pembelajaran yang ada di sekolah cenderung fokus pada buku teks yang ada, guru sebagai sumber belajar utama, guru mendominasi proses pembelajaran, hanya siswa mendengarkan dan menghafal. Inilah yang dituding sebagai kelemahan yang menyebabkan "citra" pembelajaran IPS di sekolah-sekolah dinilai kurang baik.
Jika pembelajaran IPS selama ini tetap diteruskan, terutama hanya menekankan pada informasi, fakta, dan hafalan, lebih mementingkan isi dari proses, kurang diarahkan pada proses berpikir dan kurang diarahkan pada pembelajaran bermakna dan berfungsi bagi kehidupannya, maka pembelajaran IPS tidak akan mampu membantu siswanya untuk dapat hidup secara efektif dan produktif menuju era society 5.0. Selaras dengan pendapat (Zamroni, 2000) yang menganggap bahwa siswa adalah individu yang belum dewasa, individu yang pasif sebagai objek dalam proses interaksi belajar mengajar, dan menempatkan guru sebagai pusat kegiatan belajar mengajar, tidak lagi sesuai untuk menyiapkan sumber daya manusia menuju era society 5.0, oleh karena itu sudah saatnya negara seperti Indonesia memikirkan bahkan bertindak untuk mencari berbagai strategi relevan yang kemudian diberdayakan untuk meningkatkan citra pembelajaran IPS yang bermakna menuju era society 5.0.

\section{TINJAUAN PUSTAKA}

\section{Society 5.0}

Society 5.0 adalah suatu konsep yang menyatakan bahwa teknologi akan hidup berdampingan dengan manusia untuk meningkatkan kualitas hidup secara berkelanjutan. (Sugiono, 2020). Society 5.0 mengimplementasikan teknologi pada Revolusi Industri 4.0 dengan mempertimbangkan aspek humaniora sehingga dapat menyelesaikan berbagai permasalahan sosial dan menciptakan keberlanjutan (Faruqi, 2019). Society 5.0 tidak hanya terbatas untuk faktor manufaktur tetapi juga memecahkan masalah sosial dengan bantuan integrasi ruang fisik dan virtual (Skobelev \& Borovik, 2017). Jika Industri 4.0 menempatkan teknologi hanya sebagai mesin atau alat untuk mengakses informasi, maka Society 5.0 menekankan bahwa teknologi dan fungsinya sudah menjadi bagian dari kehidupan manusia (Ellitan 2020). 


\section{Pembelajaran IPS Bermakna}

Pembelajaran IPS yang bermakna diperlukan agar siswa dapat berkomunikasi dengan terampil. Selain itu, mengajar dengan diskusi memungkinkan siswa untuk mengembangkan pemahaman tentang isu tertentu, meningkatkan keterampilan berpikir kritis dan untuk meningkatkan keterampilan interpersonal (Setyowati, 2018). Selaras dengan pernyataan Suparno (Najib \& Elhefni, 2017) Pembelajaran IPS bermakna adalah suatu proses pembelajaran dimana informasi baru dihubungkan dengan struktur pengertian yang sudah dipunyai seorang yang sedang dalam proses pembelajaran. Pembelajaran bermakna berguna untuk menumbuhkan kemampuan belajar aktif pada diri mahasiswa dan menggali kemampuan mahasiswa serta dosen untuk bersama sama berkembang dalam berbagai pengetahuan keterampilan dan pengalaman (Islami, 2021). Pembelajaran IPS bermakna terjadi apabila siswa boleh menghubungkan fenomena baru ke dalam struktur pengetahuan mereka. Artinya, bahan subjek itu mesti sesuai dengan keterampilan siswa dan mesti relevan dengan struktur kognitif yang dimiliki siswa (Faslah, 2017). Pencapaian kualitas pembelajaran merupakan tanggungjawab seorang guru dan dosen melalui penciptaan pengalaman belajar yang bermakna bagi siswa atau mahasiswa dan fasilitas yang didapat siswa atau mahasiswa untuk mencapai hasil belajar yang maksimal (Islami, 2021).

\section{Strategi pembelajaran}

Strategi pembelajaran merupakan rencana tindakan (rangkaian kegiatan) termasuk penggunaan metode dan pemanfaatan berbagai sumber daya/kekuatan dalam pembelajaran. Ini berarti penyusunan suatu strategi baru sampai pada proses penyusunan rencana kerja belum sampai pada tindakan (Syaharuddin \& Mutiani, 2020). Strategi disusun untuk mencapai tujuan tertentu.
Artinya, arah dari semua keputusan penyusunan strategi adalah pencapaian tujuan. Dengan demikian, penyusunan langkah-langkah pembelajaran, pemanfaatan berbagai fasilitas dan sumber belajar semuanya diarahkan dalam upaya pencapaian tujuan (Iif, 2011). Strategi pembelajaran sebagai komponen umum dari suatu rangkaian materi dan prosedur pembelajaran yang digunakan secara bersama-sama oleh guru dan peserta didik selama proses pembelajaran berlangsung (Solihatin, 2012). Strategi pembelajaran sebagai komponen umum dari suatu rangkaian materi dan prosedur pembelajaran yang digunakan secara bersama-sama oleh guru dan peserta didik selama proses pembelajaran berlangsung (Solihatin, 2012). Terdapat tiga hal pokok yang perlu diperhatikan dalam pemilihan atau menetukan strategi pembelajaran adalah faktor belajar (learning factors), lingkungan belajar (learning environment), dan besar kecilnya kelompok belajar (Abdul, 2012).

\section{METODE PENELITIAN}

Penelitian ini menggunakan jenis penelitian pustaka (library research) yaitu dengan penyajian data kualitatifinterpretatif, dimana objek utamanya bersumber dari berbagai buku-buku kepustakaan yang tersedia (Kohar, 2020). Penelitian pustaka juga mempelajari berbagai macam dari buku referensi ataupun hasil penelitian yang dilakukan sebelumnya secara relevan dan bermanfaat untuk kemudian memperoleh landasan teori terkait dengan masalah yang diteliti (Parinduri, 2020). Dalam penelitian ini objek utamanya ialah strategi meningkatkan citra pembelajaran IPS yang bermakna menuju era society 5.0.

\section{HASIL DAN PEMBAHASAN}

Pendidikan ilmu-ilmu sosial di Indonesia memberikan dampak nyata terhadap proses mempercepat pembangunan Zamroni (Setyowati, 2018), sedangkan menurut Krutka \& Carano 
(2016) alasan utama dari ilmu sosial adalah membantu siswa muncul sebagai warga dunia. Sejalan dengan itu (Wulandari et al., 2018) menyatakan bahwa pendidikan IPS juga memiliki peranan besar dalam membangun suatu negara. Pembelajaran IPS yang bermakna tentu akan menghasilkan generasi penerus yang berbobot untuk pengembangan negara. Selaras dengan pendapat (Hess, 2009) pembelajaran IPS sangat amat penting sebagai pengembangan yang berorientasi pada reformasi siswa), dan juga membantu siswa memahami arti penting menjadi warga negara (Barton, 2012). Guru berperan penting selama proses pembelajaran IPS dalam membangun sebuah kolaborasi dengan siswa agar terjadi interaksi yang pada akhirnya akan menimbulkan suasana belajar yang kondusif, hasil kolaborasi dalam proses pembelajaran tersebut akan memperkaya wawasan pengetahuan mereka (Sudibjo et al., 2019).

Kehidupan era society 5.0 yang diyakini penuh akan kompetisi disertai gelombang perubahan yang sedemikian cepat, secara langsung ataupun tidak mendorong guru untuk menggunakan strategi yang mumpuni guna meningkatkan kualitas pembelajarannya, termasuk pada pembelajaran IPS. Dalam hal ini kegiatan guru menjadi garda terdepan dalam upaya meningkatkan kesadaran siswa (Tarman, 2016), termasuk didalamnya menjamin siswa untuk memiliki kompetensi belajar dan berinovasi, menggunakan teknologi dan media informasi, serta dapat bekerja, bertahan dengan menguasai sejumlah kecakapan untuk hidup dan memiliki persepsi baik di dalam proses maupun hasil pada pembelajaran IPS. Strategi yang digunakan untuk meningkatakan citra pembelajaran IPS yang bermakna menuju era society 5.0 hendaknya tetap mengacu pada konsep belajar yang dicanangkan oleh komisi UNESCO dalam wujud "the four pillars of education", yaitu ("learning to know") belajar untuk mengetahui, ("learning to do") belajar melakukan sesuatu, ("learning to life together") belajar hidup bersama sebagai dasar untuk berpartisipasi dan bekerjasama dengan orang lain dalam keseluruhan aktivitas kehidupan manusia, dan ("learning to be") belajar menjadi dirinya (Delors, 1996).

Lima komponen penting yang juga harus dipersiapkan guru IPS menuju era society 5.0, yaitu, (1) educational competence, kompetensi pembelajaran berbasis internet sebagai basic skill, (2) competence for technological commercialization. Artinya seorang guru IPS harus mempunyai kompetensi yang akan membawa peserta didik memiliki sikap entrepreneurship dengan teknologi atas hasil karya inovasi peserta didik, (3) competence in globalization, yaitu, guru IPS tidak gagap terhadap berbagai budaya dan mampu menyelesaikan persoalan pendidikan, (4) competence in future strategies dalam arti kompetensi untuk memprediksi dengan tepat apa yang akan terjadi di masa depan dan strateginya, dengan cara joint-lecture, joint-research, joint-resources, staff mobility, dan rotasi, (5), conselor competence, yaitu kompetensi guru IPS untuk memahami bahwa ke depan masalah peserta didik bukan hanya kesulitan memahami materi ajar, tetapi juga terkait masalah psikologis akibat perkembangan zaman (Wahyuni, 2018). Sementara itu, Latip (Nilasari, 2020) mengemukakan bahwa setidaknya ada empat kompetensi yang harus dimiliki oleh guru pada era society 5.0, yakni, (1) guru harus mampu melakukan penilaian secara komprehensif, (2) guru harus memiliki kompetensi abad 21: karakter, akhlak dan literasi, (3) guru harus mampu menyajikan modul sesuai passion siswa (4) guru harus mampu melakukan autentic learning yang inovatif.

Sikap dan persepsi siswa didalam pembelajaran IPS perlu ditingkatkan juga sebagai faktor pendukung menuju ketercapaian pembelajaran IPS yang 
bermakna, selaras dengan pernyataan Mager (Zamroni, 2008) mengatakan bahwa sikap dan persepsi adalah kunci untuk keberhasilan siswa, siswa yang memiliki persepsi dan sikap positif terhadap suatu materi pelajaran lebih mungkin untuk melanjutkan pendidikan mereka dalam mata pelajaran atau mungkin melanjutkan pendidikan mereka melalui pelatihan teknis, perguruan tinggi, atau sekolah pascasarjana, begitu juga sebaliknya. Selanjutnya pembelajaran yang bermakna dapat dilihat dengan adanya siswa yang memiliki kekuatan dan kemampuan belajar mengembangkan diri lebih lanjut, bukan hanya memperoleh sejumlah pengetahuan, kompetensi, dan sikap, tetapi juga lebih penting adalah mengembangan kemampuan metakognisi, yaitu bagaimana pengetahuan, kompetensi, dan sikap itu diperoleh dan digunakan (Schunk, 2012).

Model pembelajaran yang berpusat pada siswa (student center learning) juga merupakan strategi untuk meningkatkan citra pembelajaran IPS yang bermakna menuju era society 5.0. Student center learning (SCL) diharapkan dapat mendorong siswa untuk menghasilkan informasi yang dimilikinya nilai atau makna untuk mengembangkan keterampilan baru (Alismail \& McGuire, 2015), seperti keterampilan berpikir kritis, pemecahan masalah, keterampilan berpikir kreatif, keterampilan metakognisi, komunikasi, kolaborasi, inovasi dan keterampilan lainnya (Johnson, 2009). Student center learning (SCL) akan memberikan hasil yang positif jika siswa terlibat secara aktif pada lingkungan belajarnya (Nichols, 2017). Hasil penelitian Warni (Setyowati, 2018) guru perlu lebih meningkatkan penggunaan model pembelajaran yang lebih mengaktifkan siswa, misalnya penggunaan model pembelajaran yang lebih kontekstual, kooperatif dan kolaboratif, inkuiri, dan pembelajaran yang berbasis masalah sehingga pembelajaran khususnya IPS menjadi lebih menarik dan bermakna.

Kualitas pembelajaran dapat ditingkatkan dengan mengubah paradigma dalam pembelajaran (Suratno et al., 2019). Pembelajaran modern menyerap teknologi terkini, yang menjadi instrumental dasar untuk pengembangan lingkungan kreatif yang dibentuk oleh metode pembelajaran baru (Karpov, 2017). Pemanfaatan berbagai jenis teknologi informasi dan komunikasi seperti jaringan internet, media pembelajaran berbasis elektronik, dan sejenisnya sangat diperlukan dalam menunjang pembelajaran IPS menuju era society 5.0. Teknologi informasi memiliki dampak positif terutama pada perkembangan intelektual siswa, mereka dapat mengembangkan memori yang lebih baik, perhatian, imajinasi spasial, dan berpikir cepat (Anisimova, 2020). Didukung pernyataan (Royani, 2020) adanya e-literasi berbantuan teknologi digital memberikan manfaat bagi guru dalam mencari berbagai informasi yang dibutuhkan dalam pembelajaran IPS yang bermakna ( Shannon, et al, 2019). Selanjutnya (Sudibjo et al., 2019) menyatakan bahwa penggunaan jaringan internet sebagai sumber belajar juga dapat mendorong siswa memperoleh informasi dengan cepat, bertukar informasi secara cepat dengan berbagai media sosial tanpa harus tatap muka. Penggunaan jaringan internet memungkinkan guru dan siswa berinteraksi melintasi ruang dan waktu, mencari bahan ajar, diskusi ataupun pembelajaran melalui video dengan mengakses berbagai situs yang tersedia secara gratis (Kamalodeen \& Charles, 2016).

Masalah sosial itu dekat dengan kehidupan siswa dan menekankan pentingnya membuat keputusan dalam hidup bermasyarakat. Untuk menjawab tantangan di atas Zamroni, n.d. (Setyowati, 2018) menawarkan tiga alternatif mempersipakan langkah ke 
depan penataan pembelajaran IPS, (1) membangun disiplin akademik sebagai core discipline, dasar keilmuan dalam IPS harus tegas sebagai basis keilmuan yang tidak akan hilang, (2) mengembangkan sosial efisiensi, perguruan tinggi perlu merencanakan pembelajaran yang memberi pengalaman mahasiswa merancang pembelajaran IPS, (3) mengembangkan peran social reconstructivist, dengan mempersiapkan mahasiswa dengan karakter yang senantiasa memerang ketidakadilan di masyarakat dengan rekayasa sosial. Guru yang ideal memiliki beberapa kualifikasi seperti komunikasi yang baik dengan siswa, sukses dalam pendidikan, sukses dalam kegiatan mengajar mata pelajarannya, bersikap penuh kasih, berprilaku baik dan penuh toleran (Aswar, 2014). Guru IPS yang baik akan memberikan pengaruh positif pada pembelajaran siswa (Halvorsen \& Wilson) mengungkapkan bahwa. Diperkuat hasil penelitian (Allazi \& Chiodo, 2004) menyatakan bahwa siswa membutuhkan pembelajaran yang bermakna, pembelajaran aktif, dan sikap antusias guru, karena aspek tersebut dianggap dapat membantu siswa dalam membentuk sikap positif. Guru memainkan peran utama dalam seberapa baik siswa memiliki persepsi tentang pelajaran, membuat siswa mencintai pembelajaran IPS atau sebaliknya. Oleh karena itu guru juga perlu kreatif dalam kegiatan pembelajaran guna menemukan cara baru dalam menangani masalah secara profesional, menjawab kebutuhan kepribadian siswa, bermotivasi kreatif dan berkemampuan pemberi solusi (Borodina, 2019).

Guru wajib diinformasikan strategistrategi mumpuni melalui berbagai hasil kajian Ilmiah yang relevan, sehingga dapat memberikan kontribusi yang kuat untuk bidangnya dalam mengatasi kesenjangan literatur, efektivitas dan praktik-praktik tradisonal pada pembelajaran IPS (Waters \& Hensley,
2020). Strategi pengajaran yang kuat dibutuhkan dalam pembelajaran IPS untuk memperdalam pencapaian siswa era informasi (IGE, 2019). Diikuti Rapoport (2020) narasi guru yang didukung buku teks dapat mempengaruhi perkembangan global siswa, yang selanjutnya dilakukan intervensi dukungan yang ditargetkan untuk memfasilitasi psikologis dan penyesuaian sosial budaya disetiap ranahnya (Bastien et al., 2018). Untuk menjadi sukses dalam menjalankan pembelajaran, sosok guru perlu memiliki nilai komitmen dan dedikasi (Chong \& Cheah, 2009), kemudian efektif dalam mentransmisikan nilai-nilai seperti ketekunan, kepedulian, dan komitmen kepada orang lain (Metzger \& Wu, 2008), dan mampu mengenal nilai-nilai dalam diri seseorang yang banyak dipengaruhi oleh pengalaman dengan orang-orang terdekatnya (Suyatno et al., 2019).

Guru wajib menyadari perbedaan masing-masing siswa yang dilihat dari tingkat kecerdasan, gaya belajar, dan tingkat dalam memahami materi. Dengan menyadari perbedaan tersebut, guru diwajibkan untuk mengambil langkah dalam mempelajari perbedaan tersebut dan menggunakan berbagai strategi mengajar untuk memastikan bahwa semua siswa dapat menikmati pembelajaran yang bermakna guna mempersipakan menuju era society 5.0 (Setyowati. 2018). Ketika guru IPS menggunakan berbagai strategi pengajaran, itu merupakan langkah positif untuk memperbaiki citra Pembelajarannya (Alazi \& Chiodo, 2004). Selanjutnya didukung hasil penelitian (Wahyudi, 2011) yang menyatakan guru seharusnya wajib mengerti terkait intelegensi siswa melalui berbagai metode pengukuran intelegensi, sehingga dalam perencanaan, proses pembelajaran hingga evaluasi belajar, guru dapat dengan mudah untuk mengoptimalkan pembelajaran IPS. Kurikulum yang dipersiapkan guru sebaiknya berisi materi atau topik pelajaran yang mau dipelajari siswa bersifat subtansif (Setyowati. 2018), 
sehingga siswa akan lebih tertarik untuk mengikuti proses pembelajaran dan dapat meningkatkan citra pada pembelajaran IPS yang lebih bermakna dalam rangka menuju era society 5.0.

\section{KESIMPULAN}

Kehidupan era society 5.0 yang diyakini penuh akan kompetisi disertai gelombang perubahan yang sedemikian cepat, secara langsung ataupun tidak mendorong guru untuk menggunakan strategi yang mumpuni guna meningkatkan kualitas pembelajarannya, termasuk pada pembelajaran IPS. Pembelajaran IPS yang bermakna diharapkan dapat memberikan konsep pemahaman kepada siswa dalam mempelajari bahkan menemukan berbagai alternatif solusi terkait fenomena sosial maupun masalah sosial menuju era society 5.0, untuk itu kontribusi guru secara nyata didalam pembelajaran IPS perlu ditingkatkan sebagai dasar awal menuju ketercapaian pembelajaran yang bermakna.

Idealnya untuk menuju era society 5.0, guru IPS wajib mengoptimalkan praktik konsep belajar yang sesuai dengan karakteristik era society 5.0, menggunakan berbagai model pembelajaran yang berpusat pada siswa (student center learning) secara aktif, inovatif dan kreatif, memberdayakan pembelajaran berbasis teknlogi informasi dan komunikasi (ICT), dan memainkan peran penting dalam meningkatkan kualitas pembelajaran dengan senantiasa memperhatikan karakteristik masingmasing siswa secara kolektif.

\section{DAFTAR PUSTAKA}

Alazzi, K., \& Chiodo, J.J. (2004). Students' perceptions of social studies: a study of middle school and high school students in jordan. International Journal of Scholarly
Acadmic Intellectual Diversity, 6(1). 1-12.

Alismail, HA, \& McGuire, P. (2015). 21st Century Standards and Curriculum: Current Research and Practice. Journal of Education and Practice, 6(6). 150-154.

Anisimova, E.S. (2020). Digital Literacy of Future Preschool Teachers. Journal of Social Studies Education Research, 11(1). 230253.

Aswar, C. (2014). Pencapaian Hasil Belajar Melalui Penumbuhan Sikap Mahasiswa. Lantanida Journal, 2(2). 202-217.

Barton, K.C. (2012). Agency, Choice, and historical action: How history teaching can help students think about democratic decision making. Citizenship Teaching \& Learning, 7(2). 131-142.

Bastien, G., Seifen-Adkins, T., \& Johnson, L. R. (2018). Striving for Success: Academic Adjustment of International Students in the U.S. Journal of International Students, 8(2). 1198-1219.

Borodina, T., Sibgatullina, A., and., Gizatullina, A. (2019). Developing Creative Thinking in Future Teachers as a Topical Issue of Higher Education. Journal of Social Studies Education Research, 10(4). 226-245.

Chong, S., \& Cheah, H. M. (2009). A Values, skills and knowledge framework for initial teacher preparation programmes. Australian Journal of Teacher Education, 34(3). 1-17.

Delors, J. (1996). Learning: The Treasure Within, Report to UNESCO of the International Commission on Education for the Twenty-First 
Century. Paris: UNESCO Publishing.

Ellitan, Lena. (2020). Competing in the Era of Industrial Revolution 4.0 and Society 5.0. Jurnal Maksipreneur, 10(1). 1-12.

Faruqi, Umar Al. (2019). Future Service in Industry 5.0. Jurnal Sistem Cerdas, 2(1). 67-79.

Faslah, R. (2017). Pemanfaatan Internet dalam Pengembangan Konsep IPS dan Implikasinya Terhadap Pembelajaran Bermakna. Econosains Jurnal Online Ekonomi Dan Pendidikan, 9(2). 167-170.

Fukuyama, Mayumi. (2018). "Society 5.0: Aiming for a New HumanCentered Society". Japan Economy Foundation JournalJapan SPOTLIGHT.

Halvorsen, A.L., \& Wilson, S.M. (2010). General Challenges in Social Studies Teacher Education. International Encyclopedia of Education, 719-724.

Hess, D.E. (2009). Controversy in the Classroom The Democratic Power of Discussion. Routledge Press.

IGE, O. (2019). Using Action Learning, Concept-Mapping, and Value Clarification to Improve Students' Attainment in ICT Concepts in Social Studies: The Case of Rural Learning Ecologies. Journal of Social Studies Education Research. 10(1).301-322.

Iif, k. A. (2011). Stategi Pembelajaran Sekolah Terpadu. Jakarta: Prestasi Pustaka Publisher.

Irawan, E. (2020). Pelatihan Blended Learning Sebagai Upaya Menghadapi Masyarakat 5.0. Jurnal Pengabdian kepada Masyarakat, 4(2).190 -198.
Islami, F. H. (2021). Kajian Literatur Model Pembelajaran Bermakna (Meaningful Learning). https://doi.org/10.31219/osf.io/dm 284.

Karpov, A.O. (2017). Education for Knowledge Society: Learning and Scientific Innovation Environment. Journal of Social Studies Education Research. 8(3), 201-214.

Kamalodeen, V.J., and Charles, M.J. (2016). A Mixed Methods Research Approachto Exploring Teacher Participation in an Online Social Networking Website. International, Journal of Qualitative Methods, 15(1). 1-14.

Krutka, G.K., \& Carano, K.T. (2016). Videoconferencing for Global Citizenship Education: Wise Practices for Social Studies Educators. Journal of Social Studies Education Research, 7(2). 109-136.

Kohar, A. (2020). Islamic Theology And Rasionalism: Analisis Pemikiran Sutan Takdir Alisyahbana. Tribakti: Jurnal Pemikiran Keislaman, 31(1), 103-122.

Mardiati \& Leba. (2018). Employing Food Bank in Civic Education as a Pedagogical Tool in Project-based Learning. Journal of Social Studies Education Research, 9(4). 352-363.

Metzger, S. A., \& Wu, M. (2008). Commercial teacher selection instruments: The validity of selecting teachers through beliefs, attitudes, and values. Review of Educational Research, 78(4). 921-940.

Najib, D., \& Elhefni, E. (2017). Pengaruh Penerapan Pembelajaran Bermakna (Meaningfull Learning) 
Pada Pembelajaran Tematik IPS Terpadu Terhadap Hasil Belajar Siswa Kelas III di MI Ahliyah IV Palembang. JIP (Jurnal Ilmiah PGMI), 2(1). 19-28.

Nichols, J.R. (2017). 4 Essential Rules Of 21st Century Learning. Retrieved from

https://www.teachthought.com/lea rning/4-essential-rules-of-21stcentury-learning/.

Nilasari, S. 2020. Pendidikan di Era Revolusi Industri 5.0 Terhadap Disiplin Kerja Guru. Palembang: Prosiding Seminar Nasional Pendidikan Program Pascasarjana Universitas PGRI Palembang. 759-804.

NEA (National Education Association). 2017. Preparing 21st Century Students for a Global Society: An Educator's Giude to the "Four Cs".

Parinduri, M.A., Karim, A., Lestari, H. (2020). Main Values of Toba Muslim Batak Culture in Moral Education Perspective. Karsa: Journal of Social and Islamic Culture, 28(1). 121-140.

Rapoport, Anatoli. (2020). Development of Global Identity in the Social Studies Classroom. Journal of Social Studies Education Research. 11(1). 1-20.

Royani, I. (2020). Peningkatan Kompetensi Guru Menuju Era Revolusi Industri 5.0. Palembang: Prosiding Seminar Nasional Pendidikan Program Pascasarjana Universitas PGRI Palembang. 449-456.

Salgues, B. (2018). Society 5.0 Industry of the Future, Technologies, Methods and Tools. London: ISTE Ltd.

Schunk, Daleh H. 2012. Teori-teori Pembelajaran: Perspektif
Pendidikan. Yogyakarta: Pustaka Pelajar.

Setyowati, R., Firmansyah., W. (2018). Upaya Peningkatan Citra Pembelajaran IPS Bermakna di Indonesia. Jurnal Pendidikan Ilmu Pengetahuan Sosial Indonesia, 3(1). 14-17.

Shannon, C., Reilly, J., and Bates, J. (2019). Teachers and information literacy: Understandings and perceptions of the concept. Journal of Information Literacy. 13(2), 41-72.

Skobelev, P., \& Borovik, Y. S. (2017). On The Way From Industri 4.0 To Industri 5.0: From Digital Manufactureing To Digital Society. International Scientific Research Journal Industri4.0, 307- 311.

Solihatin, E. (2012). Strategi Pembelajaran PPKN. Jakarta: Bumi Aksara.

Sudibjo, N., Idawati, L., Harsanti, H.G. R. (2019). Characteristics of Learning in the Era of Industry 4.0 and Society 5.0. International Conference on Education Technology (ICoET 2019). Advances in Social Science, Education and Humanities Research, volume 372. Atantis press.

Sugiono, Shiddiq. (2020). Industri Konten Digital dalam Perspektif Society 5.0 Digital Content Industry in Society 5.0 Perspective. Jurnal IPTEK-KOM (Jurnal Ilmu Pengetahuan dan Teknologi Komunikasi), 22(2). 175-191.

Suratno., Komaria, N., Yushardi., Dafik., and Wicaksono, I. (2019). The Effect of Using Synectics Model on Creative Thinking and Metacognition Skills of Junior 


High School $\begin{gathered}\text { Students. } \\ \text { International Journal of } \\ \text { Instruction, 12(3). 133-150. }\end{gathered}$

Suyatno., Pambudi D.I., Mardiati, A., Wantini., Nuraini, E., and Yoyo. (2019). The Education Values of Indonesian Teachers: Origin, Importance, and Its Impact on Their Teaching. International Journal of Instruction. 12(3). 633650.

Syaharuddin \& Mutiani. (2020). Strategi Pembelajaran IPS: Konsep dan Aplikasi. Banjarmasin: Program Studi Pendidikan IPS Fakultas Keguruan dan Ilmu Pendidikan Universitas Lambung Mangkurat.

Tarman, B. (2016). Innovation and Education. Research in Social Sciences and Technology, 1(1).7797.

Uge, S., Neolaka, A., Yasin., M. (2019). Development of Social Studies Learning Model Based on Local Wisdom in Improving Students' Knowledge and Social Attitude. International Journal of Instruction, 12(3). 375-388.

Wahyudi, D. (2011). Pembelajaran IPS Berbasis Kecerdasan Intrapersonal Interpersonal dan Eksistensial. Jornal Penelitian Pendidikan, (1). 33-45.

Wahyuni, D. (2018). Peningkatan Kompetensi Guru Menuju Era Revolusi Industri 5.0. Info Singkat (Kajian Singkat Terhadap Isu Aktual dan Strategis) Pusat Penelitian Badan Keahlian DPR RI, X(24)/II/Puslit/Desember/2018. 13-18.

Waters, S., \& Hensley, M. (2020). A National Survey of US Social Studies Teacher Educators' Professional Habits and
Preferences. Journal of Social Studies Education Research. 11(3). 1-17.

Wulandari, T., Supardi., Nasiwan., Marini, T. (2018). Identifikasi Problematika Pembelajaran IPS (Kajian di SMPN 5 Yogyakarta, SMPN 8 Yogyakarta, dan SMP Muhammadiyah 1 Yogyakarta). Yogyakarya: staffnew.uny.ac.id.

Zamroni. (2008). Teaching social studies. Yogyakarta: UNY.

Zamroni. (2000). Paradigma Pendidikan Masa Depan. Yogyakarta: Bigraf Publishing. 